\title{
Comportamiento frente a la corrosión y biocompatibilidad in vitro/in vivo de la aleación AZ31 modificada superficialmente ${ }^{(\cdot)}$
}

\author{
M. Carboneras*, C. Iglesias**, B.T. Pérez-Maceda***, J.A. del Valle*, M.C. García-Alonso*, M.A. Alobera*, \\ C. Clemente****, J.C. Rubio**, M.L. Escudero* y R.M. Lozano***
}

Resumen

\begin{abstract}
En el presente trabajo se ha estudiado el comportamiento frente a la corrosión y la biocompatibilidad in vitro/in vivo de la aleación de magnesio AZ31, cuyas propiedades mecánicas son superiores a los requisitos mecánicos del hueso. La aleación en estado de recepción ha mostrado una cinética de corrosión no compatible con el crecimiento celular. Para mejorar su comportamiento, el material ha sido modificado superficialmente mediante tratamiento de conversión química en ácido fluorhídrico. La capa de fluoruro de magnesio generada tras este tratamiento mejora el comportamiento del material frente a la corrosión, permitiendo el crecimiento in vitro de células osteoblásticas sobre su superficie y la formación in vivo de una capa de nuevo tejido óseo muy compacta. Estos resultados permiten concluir que el recubrimiento de fluoruro de magnesio es necesario para que el material AZ31 pueda ser potencialmente aplicado como implante biodegradable y reabsorbible en reparaciones óseas.
\end{abstract}

\section{Corrosion behaviour and in vitro/in vivo biocompatibility of surface-modified AZ31 alloy}

\begin{abstract}
The present work evaluates the corrosion behaviour and the in vitro/in vivo biocompatibility of the AZ31 magnesium alloy, which fulfills the mechanical requirements of bone. The corrosion kinetic of as-received AZ31 alloy was not compatible with the cell growth. To improve its performance, the AZ31 alloy was surface modified by a chemical conversion treatment in hydrofluoric acid. The magnesium fluoride layer generated by the surface treatment of AZ31 alloy enhances its corrosion behaviour, allowing the in vitro growth of osteoblastic cells over the surface and the in vivo formation of a highly compact layer of new bone tissue. These results lead to consider the magnesium fluoride coating as necessary for potential use of the AZ31 alloy as biodegradable and absorbable implant for bone repair.
\end{abstract}

Keywords

AZ31; Magnesium fluoride; Corrosion; Biocompatibility; In vitro/in vivo.

\section{INTRODUCCIÓN}

Los materiales metálicos, como los aceros inoxidables o el titanio y sus aleaciones, son utilizados habitualmente como implantes temporales de osteosíntesis, en forma de placas y tornillos, debido a su elevada resistencia a la corrosión y adecuada biocompatibilidad en el organismo. No obstante, si estos implantes permanecen en el cuerpo durante un periodo prolongado de tiempo acaban liberando cationes metálicos ${ }^{[1]}$ que pueden ser tóxicos para el organismo, siendo por ello conveniente su retirada en una segunda intervención quirúrgica una vez cumplida su misión de reparación. Este problema puede ser resuelto empleando implantes biodegradables y reabsorbibles, que gradualmente se disuelven y eliminan una vez conseguida la reparación ósea. En este contexto, el magnesio y sus aleaciones pueden ser biomateriales más idóneos que cualesquiera otros implantes, metálicos o poliméricos, para aplicaciones relacionadas

\footnotetext{
(•) Trabajo recibido el día 02 de Diciembre de 2010 y aceptado en su forma final el día 15 de Febrero de 2011.

* Centro Nacional de Investigaciones Metalúrgicas (CENIM), Consejo Superior de Investigaciones Científicas (CSIC), Madrid, España.

** Hospital La Paz, Madrid, España.

*** Centro de Investigaciones Biológicas (CIB), Consejo Superior de Investigaciones Científicas (CSIC), Madrid, España.

**** Facultad de Medicina, Universidad de Alcalá de Henares (UAH), Madrid, España.
} 
con la reparación del hueso ${ }^{[2}$ y 3$]$. Entre sus características, los valores de densidad, módulo elástico y resistencia a la compresión del magnesio son más cercanos a los del hueso que la de los materiales empleados actualmente en aplicaciones endoprotésicas. Además, el magnesio es un elemento necesario para la incorporación del calcio al hueso ${ }^{[4]}$ y para la estimulación del crecimiento de nuevo tejido, no siendo tóxico y degradándose en los fluidos del cuerpo, lo que le hace particularmente apropiado para aplicaciones ortopédicas. No obstante, el magnesio presenta una velocidad de corrosión muy elevada en medio fisiológico, lo que hace necesaria la aplicación de estrategias para controlar su cinética de degradación ${ }^{[5}$ y 6$]$, comprendiendo desde la modificación del procesado metalúrgico del material[ ${ }^{[7]}$, la variación del tamaño de grano ${ }^{[8]}$, la adición de elementos aleantes $^{[9}$ y 10] hasta la aplicación de recubrimientos y tratamientos de modificación superficial ${ }^{[11-13]}$.

En el presente trabajo se ha estudiado el comportamiento frente a la corrosión de la aleación de magnesio AZ31 (Mg-Al-Zn) y se ha evaluado el efecto que ejerce la aplicación de un recubrimiento de fluoruro de magnesio en el comportamiento del material. Se ha llevado a cabo un estudio comparativo del material, en estado de recepción y modificado superficialmente, mediante diferentes aproximaciones experimentales, evaluando la corrosión en medio de cultivo celular y la biocompatibilidad in vitro en cultivos celulares e in vivo en ratas Wistar.

\section{PROCEDIMIENTO EXPERIMENTAL}

\subsection{Material y modificación superficial}

El material objeto de estudio ha sido la aleación de magnesio AZ31, suministrada por Elektron Limited, $U K$, en forma de chapa laminada de $3 \mathrm{~mm}$ de espesor en la condición "O-temper" consistente en un tratamiento de recocido a $345^{\circ} \mathrm{C}$, que equivale a un tratamiento de solubilización por el cual el material de recepción no presenta la fase $\mathrm{Mg}_{17}(\mathrm{Al}, \mathrm{Zn})_{12}$. La composición química del material analizada mediante fluorescencia de rayos X de dispersión por longitud de onda (WDXRF) es la siguiente: 3,37 \% Al, 0,78\% Zn, 0,22 \% Mn y 95,63 \% Mg (porcentajes en peso). Se ensayaron muestras cuadradas de dimensiones $10 \times 10 \mathrm{~mm}^{2}$ con un acabado superficial de desbaste con papel de lija de $\mathrm{SiC}$ para agua hasta grado 1.200. Una vez lijadas, las muestras fueron lavadas con etanol en baño de ultrasonido y secadas mediante chorro de aire. Los estudios se realizaron para la aleación
AZ31 en estado de recepción y modificada superficialmente mediante un tratamiento de conversión química. Dicho tratamiento consistió en la inmersión de las muestras en una solución de ácido fluorhídrico al 48 \% con agitación a temperatura ambiente durante $24 \mathrm{~h}^{[11 \text { y } 12]}$. Una vez finalizado el tratamiento, las muestras se lavaron con agua destilada y se secaron mediante chorro de aire.

\subsection{Microestructura y caracterización mecánica}

La microestructura del material fue examinada por microscopía óptica (MO). Las muestras, previamente lijadas con $\mathrm{SiC}$, fueron pulidas mecánicamente con pasta de diamante de $6 \mathrm{~m} \mathrm{~m}$ y de $1 \mathrm{~m} \mathrm{~m}$, realizando un pulido final con sílice coloidal. La estructura de grano fue determinada tras sucesivos ataques en una solución de etanol $(100 \mathrm{ml})$, ácido pícrico $(5 \mathrm{~g})$, ácido acético $(5 \mathrm{ml})$ y agua $(10 \mathrm{ml})$. El tamaño de grano medio se determinó mediante el método de intersección lineal.

El comportamiento mecánico del material se caracterizó mediante la realización de ensayos de tracción en probetas planas de $10 \mathrm{~mm}$ de longitud útil y $2 \times 4 \mathrm{~mm}^{2}$ de sección, con el eje de tracción paralelo a la dirección de laminación. Las muestras se ensayaron a una velocidad de deformación constante de $10^{-3} \mathrm{~s}^{-1}$ a temperatura ambiente.

\subsection{Ensayos de corrosión}

Los mapas del potencial superficial de la aleación AZ31 en estado de recepción y modificada superficialmente se obtuvieron mediante sonda Kelvin de barrido (SKP). Las medidas se realizaron mediante el empleo de una punta de Pt de $50 \mu \mathrm{m}$ de diámetro, efectuando barridos sobre áreas de $3 \times 3 \mathrm{~mm}^{2}$ a temperatura ambiente con una humedad relativa del $95 \%$, obteniendo potenciales relativos al potencial del electrodo normal de hidrógeno (SHE).

El comportamiento frente a la corrosión se evaluó mediante medidas de espectroscopía de impedancia electroquímica (EIS). Los ensayos se llevaron a cabo utilizando un Solartron 1280 en una celda electroquímica convencional de tres electrodos, utilizando un alambre de Pt como contraelectrodo y un electrodo de $\mathrm{Ag} / \mathrm{AgCl}$ como electrodo de referencia. El área del electrodo de trabajo fue de $0,5 \mathrm{~cm}^{2}$. Como electrolito se empleó el mismo medio utilizado en los ensayos in vitro con cultivos 
celulares: DMEM (Dulbecco's Modified Eagle Medium) suplementado con $10 \%$ de suero fetal bovino y antibióticos (penicilina $100 \mathrm{U} / \mathrm{ml}$ y estreptomicina $100 \mu \mathrm{g} / \mathrm{ml}$ ). Las renovaciones del medio se llevaron a cabo a las $24 \mathrm{~h}$ de comenzar el ensayo y posteriormente cada 48 h hasta la finalización del experimento, siguiendo así el mismo protocolo experimental que en los ensayos in vitro con cultivos celulares. Las medidas electroquímicas se realizaron en función del tiempo de inmersión en medio de cultivo celular en el entorno del potencial de corrosión $\left(\mathrm{E}_{\text {corr }}\right)$, aplicando una onda sinusoidal de potencial de $10 \mathrm{mV}$ de amplitud en un intervalo de frecuencias de $20 \mathrm{kHz}$ a $1 \mathrm{mHz}$, tomando cinco frecuencias equiespaciadas por cada década logarítmica.

Los resultados experimentales de impedancia electroquímica fueron analizados ajustándolos según diferentes modelos de circuitos equivalentes. Los parámetros de los circuitos equivalentes fueron calculados según un programa no lineal de mínimos cuadrados para todo el rango de frecuencias medidas. El criterio usado para estimar la calidad del ajuste fue analizado en primer lugar por el menor valor de $\mathrm{C}^{2}$ y en segundo lugar por el error más bajo estimado (en porcentaje) para todos los componentes.

\subsection{Ensayos con cultivos celulares}

Los materiales a ensayar se esterilizaron por ambas caras con luz ultravioleta durante 5 min en una campana de flujo laminar. Los cultivos in vitro se realizaron con dos líneas celulares de tipo osteoblástico: la línea de osteosarcoma humano Saos-2 y la línea no tumoral de calvaria de ratón MC3T3-E1. Ambas líneas fueron cultivadas en DMEM suplementado con suero fetal bovino y antibióticos, que es el medio que también se utilizó para las medidas de corrosión. La concentración de células sembradas sobre la aleación AZ31 en estado de recepción y modificada superficialmente fue de 50.000 células $/ \mathrm{ml}$ y 40.000 células/ml, para las líneas Saos-2 y MC3T3-E1, respectivamente, en un volumen de $1 \mathrm{ml}$. La duración de los experimentos fue de 11 días para la línea Saos-2 y 7 días para la línea MC3T3-E1, tiempos en los que los respectivos cultivos alcanzaban la confluencia en ausencia de los materiales en estudio. Durante los ensayos las muestras metálicas se observaron en la propia placa de cultivo en el microscopio invertido y una vez finalizados los ensayos se observaron bajo el microscopio. Para visualizar el crecimiento de células osteoblásticas sobre la superficie del material de ensayo, las células fueron fijadas. Para ello se añadió a cada pocillo de la placa $1 \mathrm{ml}$ de metanol frío y se incubó a $-20^{\circ} \mathrm{C}$ durante $10 \mathrm{~min}$, seguido de un lavado con PBS y posterior incubación durante $10 \mathrm{~min}$ a temperatura ambiente con $1 \mathrm{ml}$ de una solución de $2 \mu \mathrm{g} / \mathrm{ml}$ Hoechst $33258^{[14]}$ en PBS. El reactivo Hoechst es un colorante que se une al ADN celular y emite fluorescencia cuando es iluminado con luz ultravioleta, permitiendo visualizar la presencia de células. De esta forma, las muestras se pudieron observar en un microscopio multidimensional Leica AF6000 LX utilizando luz ultravioleta. Todos los ensayos fueron realizados por triplicado.

\subsection{Ensayos in vivo}

En la experimentación animal se siguieron las normas de la Directiva Comunitaria sobre animales de experimentación (86/609CEE), así como la normativa española (RD 1201/2005).

Como material biológico se utilizaron 18 ratas Wistar, hembras de tres meses de edad y con un peso aproximado de $200 \mathrm{~g}$. Los materiales en estudio se implantaron en una localización supraperióstica (encima del hueso) en la calota de las ratas. Los materiales insertados fueron muestras cuadradas de dimensiones $6 \times 6 \mathrm{~mm}^{2}$ y $1 \mathrm{~mm}$ de espesor, las cuales permanecieron en los animales durante 7, 24 y 48 días para evaluar su cinética de biodegradación por método gravimétrico una vez extraídas del animal. Finalizados estos ensayos, los tejidos en contacto con el material en estudio fueron incluidos en parafina para su análisis histológico. El estudio para cada material y tiempo se llevo a cabo por triplicado.

\section{RESULTADOS Y DISCUSIÓN}

\subsection{Microestructura y caracterización mecánica de la aleación AZ31}

La figura 1 muestra la microestructura de la aleación AZ31. El tamaño de grano medio es $25,7 \mathrm{~m} \mathrm{~m}$. La microestructura presenta partículas de una fase rica en $\mathrm{Mn}\left(\mathrm{Al}_{6} \mathrm{Mn}\right)$, cuya fracción en volumen, determinada mediante técnicas de análisis de imagen, se estima próxima a $3 \times 10^{-3}[8]$.

La figura 2 muestra la curva tensión-deformación para la aleación AZ31 estudiada. Para destacar la relevancia de la microestructura, se compara con la curva tensión-deformación de la aleación AZ31 colada, con un tamaño de grano cercano a $\mathrm{d}=2 \mathrm{~mm}$. Como se aprecia en la figura 2, la aleación laminada, 


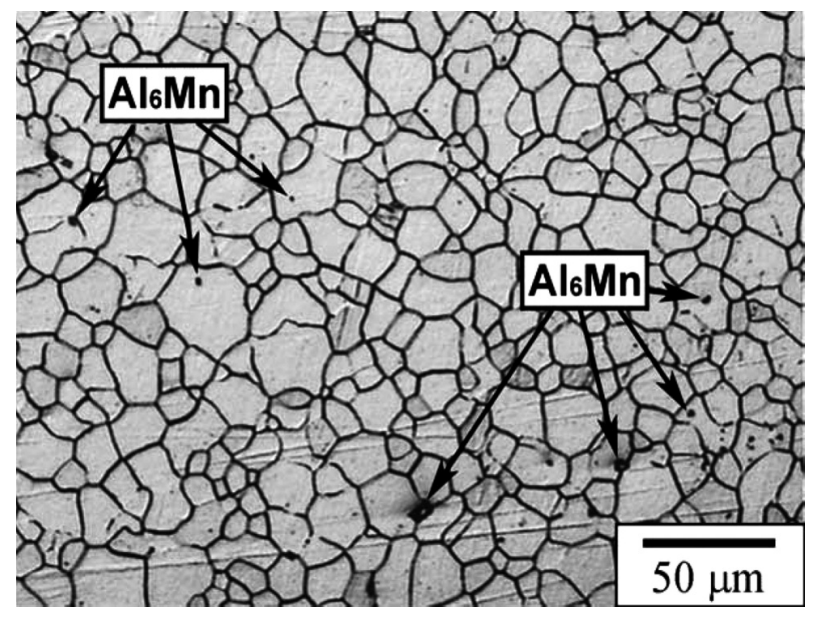

Figura 1. Micrografía de la aleación de magnesio AZ31.

Figure 1. AZ31 magnesium alloy micrograph.

al poseer un tamaño de grano fino y una textura basal característica de la laminación ${ }^{[15]}$, posee un límite elástico de $150 \mathrm{MPa}$ (medido a una deformación del 0,2 \%) y una tensión máxima de $300 \mathrm{MPa}$, valores que son muy superiores a los de la misma aleación en estado de colada y son más elevados que los requisitos mecánicos del hueso natural ${ }^{[16]}$.

\subsection{Ensayos de corrosión}

La figura 3 muestra los mapas de potencial mediante sonda Kelvin de la superficie de la aleación AZ31 en estado de recepción (Fig. 3 a)) y modificada superficialmente por tratamiento de conversión química en ácido fluorhídrico (Fig. 3 b)), tras 6 h de exposición en atmósfera de aire a temperatura ambiente y con una humedad relativa del $95 \%$. Estos mapas dan información sobre la reactividad electroquímica de la superficie del material. El mapa de potenciales muestra que el valor de potencial medio aumenta alrededor de unos 0,4 V tras el tratamiento en ácido fluorhídrico, lo que indica que la superficie del material AZ31 después de aplicar el tratamiento se ennoblece, mostrando de esta manera el carácter protector de la capa de fluoruro de magnesio. Estos resultados están de acuerdo con trabajos previos en los que se ha demostrado que el magnesio recubierto con fluoruro de magnesio presenta un buen comportamiento a la corrosión ${ }^{[12-17]}$.

La figura 4 presenta los diagramas de Nyquist de la aleación AZ31, en estado de recepción y con recubrimiento de fluoruro de magnesio. En el caso del material en estado de recepción (Fig. 4 a)), los espectros obtenidos muestran la formación de semicírculos capacitivos, asignados a la resistencia de transferencia de carga $\left(R_{t}\right)$, o lo que es lo mismo, a la resistencia a la

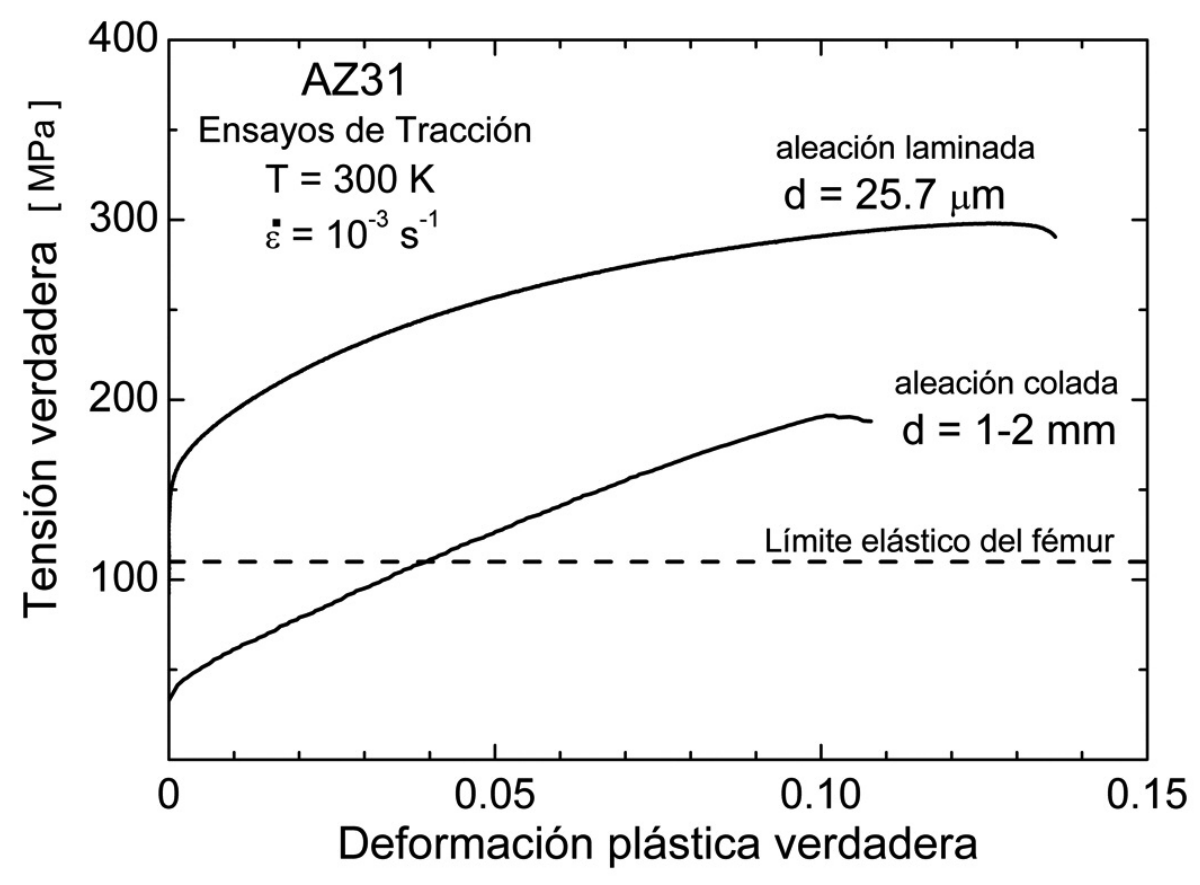

Figura 2. Curvas tensión-deformación verdadera obtenidas mediante ensayos de tracción para la aleación de magnesio AZ31.

Figure 2. True stress versus true plastic strain during tensile tests for the AZ31 magnesium alloy. 

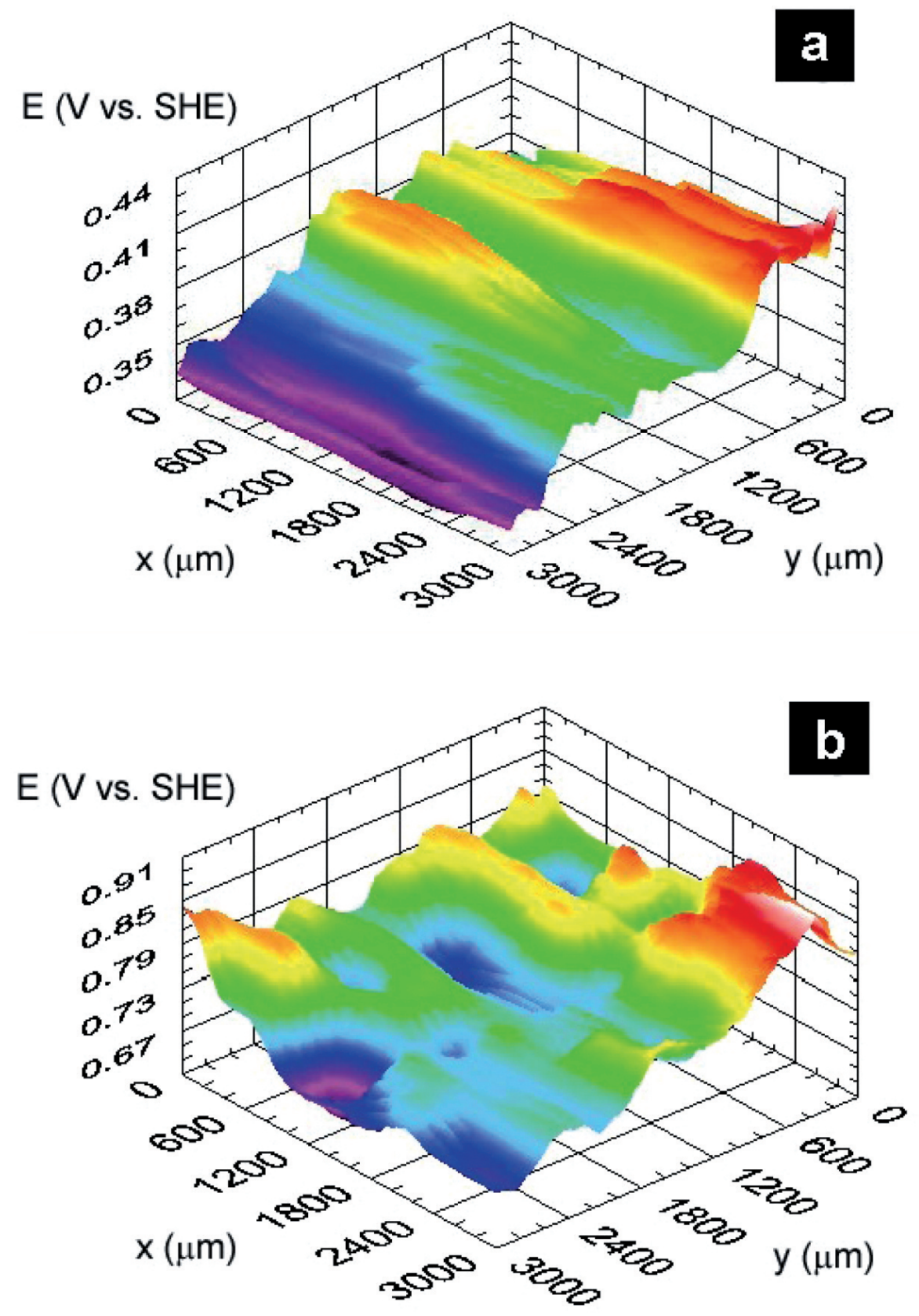

Figura 3. Mapas de potencial obtenidos por SKP para la aleación de magnesio AZ31: a) en estado de recepción y b) con recubrimiento de fluoruro de magnesio.

Figure 3. SKP potential maps for the AZ31 magnesium alloy: a) asreceived and b) magnesium fluoride-coated.

corrosión. Se observa que el diámetro del semicírculo disminuye con el tiempo de inmersión en el medio de cultivo celular, indicando la pérdida progresiva de resistencia a la corrosión del material con el tiempo. Sin embargo, cuando la aleación se encuentra recubierta con fluoruro de magnesio, la resistencia a la corrosión del material aumenta significativamente, según se observa en la figura 4 b), donde la amplitud de los arcos obtenidos aumenta con respecto a los registrados para el material en estado de recepción. De hecho, para tiempos cortos de inmersión (1 día) la aleación muestra un compor- 

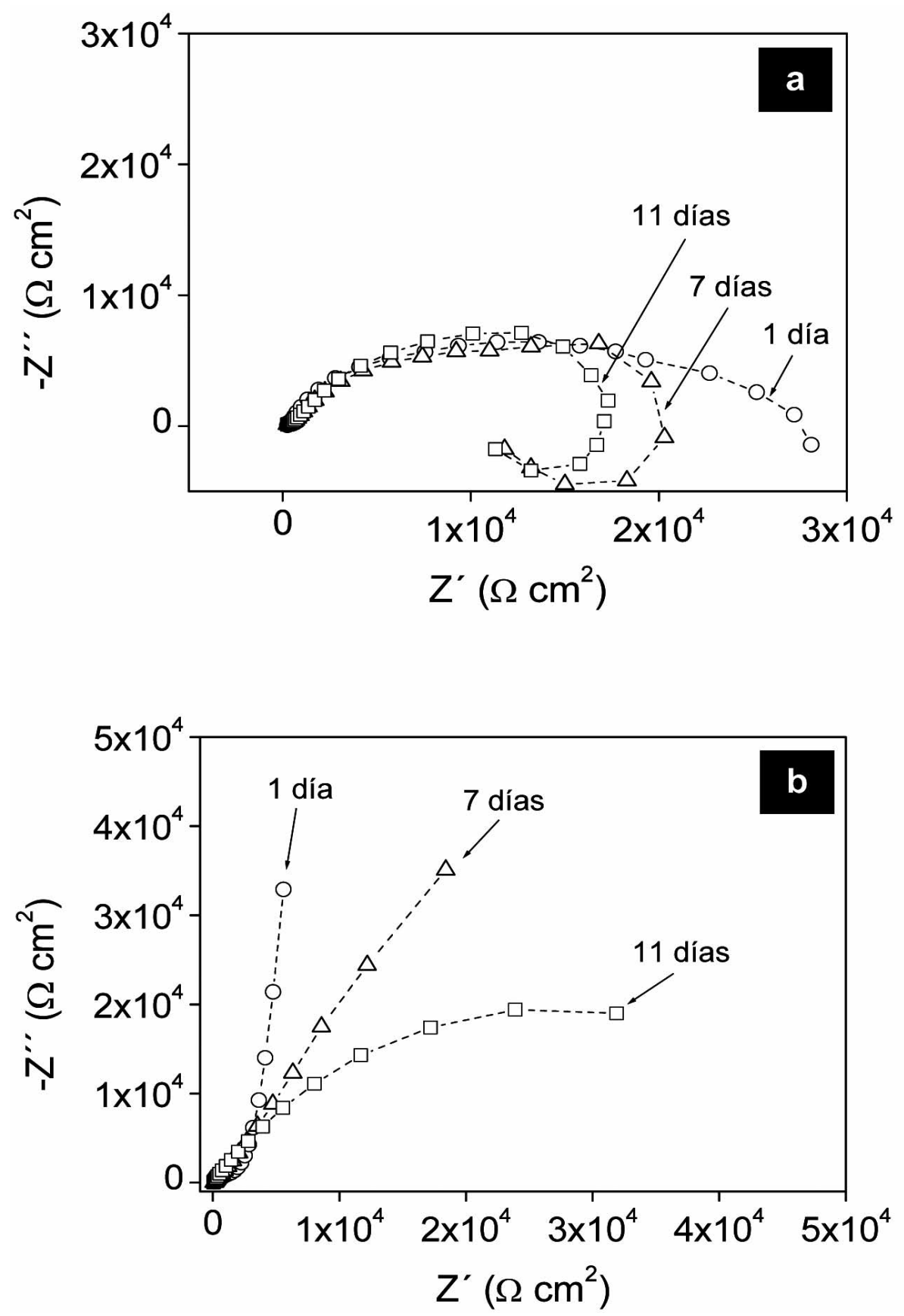

Figura 4. Evolución de los diagramas de Nyquist con el tiempo de inmersión en medio de cultivo celular para la aleación de magnesio AZ31: a) en estado de recepción y b) con recubrimiento de fluoruro de magnesio.

Figure 4. Nyquist diagrams evolution over immersion time in cell culture medium for the AZ31 magnesium alloy: a) as-received and b) magnesium fluoride-coated.

tamiento altamente capacitivo, caracterizado por una respuesta en impedancia prácticamente paralela al eje imaginario del diagrama de Nyquist que se asocia al efecto protector del recubrimiento generado. Al aumentar el tiempo de inmersión ( 7 días) el arco capacitivo tiende a abatirse sobre el eje real, encontrándose claramente definido a los 11 días de experimentación. Para este tiempo, el material recubierto (Fig. 4 b)) muestra un comportamiento frente a la corrosión muy similar al mostrado por la aleación en 
estado de recepción transcurrido 1 día de ensayo (Fig. 4 a)), con valores de $R_{t}$ del orden de $3 \times 10^{4} \mathrm{~W} \mathrm{~cm}^{2}$. A partir de los datos de impedancia obtenidos para la aleación AZ31, en estado de recepción y con recubrimiento en medio de cultivo celular, el comportamiento electroquímico de los sistemas en estudio pueden ajustarse mediante los circuitos equivalentes que se proponen en la figura 5 . Con objeto de verificar los modelos propuestos, la tabla 1 presenta los parámetros electroquímicos obtenidos experimentalmente, la capacidad de la doble capa electroquímica $C_{d l}$ y la resistencia de transferencia $R_{t}$ y los parámetros obtenidos mediante simulación que son el elemento de fase constante, $\mathrm{CPE}_{\mathrm{dl}}$ que simula la capacidad de la doble capa electroquímica y la resistencia de transferencia $R_{t}$, para dos tiempos de ensayo, 1 y 11 días, que corresponden al primer y último día de ensayo. Según los datos obtenidos, el proceso de corrosión que sufre la aleación AZ31 en estado de recepción desde el primer día de inmersión en el medio corrosivo puede representarse mediante un circuito simple de Randles (Fig. 5 a)), donde $\mathrm{R}_{\mathrm{s}}$ es la resistencia del electrolito, $\mathrm{CPE}_{\mathrm{dl}}$ se adscribe a la pseudo capacidad de la doble capa electroquímica formada en la interfase metal/electrolito y $\mathrm{R}_{t}$ es la resistencia a la transferencia de carga. Los valores de la tabla 1 muestran que existe buena concordancia entre los datos experimentales y los ajustados. En ambos casos la resistencia de transferencia disminuye ligeramente con el tiempo de inmersión y la capacidad presenta valores típicos de la doble capa electroquímica.

En el caso de la aleación AZ31 con recubrimiento de fluoruro de magnesio en el medio corrosivo (Fig. 5 b)), el circuito equivalente está formado por la pseudo capacidad $\mathrm{CPE}_{c}$ y resistencia $\mathrm{R}_{c}$ que representan el carácter protector del recubrimiento de fluoruro de magnesio, unido en serie al circuito de Randles asociado al proceso de corrosión. Según este nuevo circuito se puede observar de nuevo, en los valores de la tabla 1 que existe también buena concordancia entre los datos experimentales $\mathrm{R}_{c}$ y $\mathrm{C}_{c}$ y los ajustados $\mathrm{R}_{c} \mathrm{y}$ $\mathrm{CPE}_{\mathrm{c}}$. Con el aumento del tiempo de inmersión del material recubierto en el medio agresivo (11 días), la pérdida de las propiedades protectoras del recubrimiento conduce al sistema a un proceso de corrosión similar al del material en estado de recepción para el primer día de ensayo en medio de cultivo celular (Fig. 5 a)).

\subsection{Ensayos de biocompatibilidad in vitro}

Los ensayos con la aleación AZ31 en estado de recepción en medio de cultivo celular, tanto en ausencia como en presencia de células Saos-2 y MC3T3-E1, mostraron un gran desprendimiento de burbujas que a

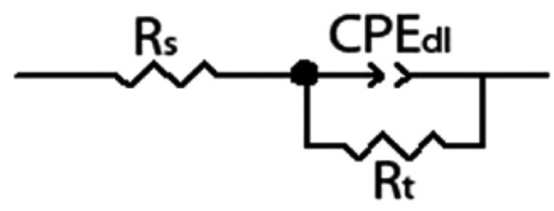

b

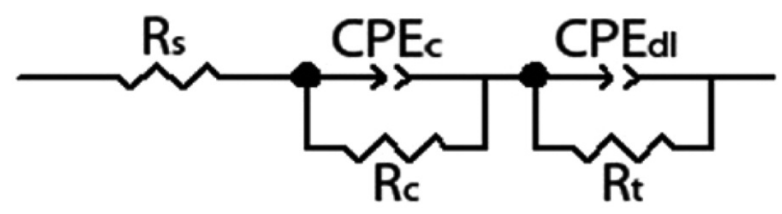

Figura 5. Circuitos equivalentes que simulan el comportamiento electroquímico del sistema, según los datos experimentales de impedancia: a) proceso de corrosión y b) protección del recubrimiento seguido del proceso de corrosión. El significado de los parámetros representados es el siguiente: $R_{s}$ es la resistencia del electrolito, $\mathrm{CPE}_{\mathrm{dl}}$ se adscribe a una pseudo capacidad de la doble capa electroquímica y $R_{t}$ es la resistencia a la transferencia de carga; $\mathrm{CPE}_{\mathrm{c}}$ y $\mathrm{R}_{\mathrm{c}}$ representan la pseudo capacidad y la resistencia asociadas al carácter protector del recubrimiento.

Figure 5. Equivalent circuits to simulate the electrochemical behaviour, according to the experimental impedance data: a) corrosion process and b) coating protection together with the corrosion process. The meaning of the represented parameters is as follows: $R_{S}$ is the electrolyte resistance; $C P E_{d l}$ is ascribed to the pseudo double layer capacitance and $R_{t}$ is the charge transference resistance; $C P E_{c}$ and $R_{c}$ are the pseudo capacitance and resistance of the protective character of the coating.

se mantuvo durante todo el ensayo, producido como consecuencia de la liberación de hidrógeno durante el proceso de corrosión del material ${ }^{[18]}$. La figura 6 a) ilustra el proceso de corrosión por picadura que se produce en la aleación AZ31 en estado de recepción tras 11 días de exposición al cultivo celular. Asímismo se observó un precipitado blanquecino, no muy abundante, en el pocillo de cultivo y sobre la superficie del material metálico. La presencia de este precipitado, que corresponde a óxidos e hidróxidos de magnesio, podría justificar la escasa biocompatibilidad observada para este material, ya que se observaron pocas células únicamente en el borde del pocillo de cultivo, es decir, en la zona más alejada del material. 
Tabla 1. Datos experimentales obtenidos de los ensayos de impedancia electroquímica y datos de ajuste generados con los circuitos equivalentes propuestos (Fig. 5) para la aleación de magnesio AZ31 en medio de cultivo celular: a) en estado de recepción y b) con recubrimiento de fluoruro de magnesio

Table 1. Experimental data from electrochemical impedance measurements and fitting data from the proposed equivalents circuits (Fig. 5) for the AZ31 magnesium alloy in cell culture medium: a) as-received material and b) magnesium fluoride coated material

\begin{tabular}{|c|c|c|c|c|c|c|c|c|c|c|}
\hline \multicolumn{5}{|c|}{ Experimental } & \multicolumn{6}{|c|}{ Simulación } \\
\hline & $\begin{array}{cc}\mathbf{t} & \mathbf{R}_{\mathrm{s}} \\
\text { (d) } & (\mathrm{W})\end{array}$ & $\begin{array}{c}R_{c} \\
\left(W \cdot \mathrm{cm}^{2}\right)\end{array}$ & $\begin{array}{c}\mathrm{C}_{\mathrm{c}} \\
\left(\mathrm{F} \cdot \mathrm{cm}^{-2}\right)\end{array}$ & $\underset{\left(W \cdot \mathrm{cm}^{2}\right)}{\mathbf{R}_{\mathrm{c}}} \underset{\left(\mathbf{F} \cdot \mathrm{cm}^{-2}\right)}{\mathrm{C}_{\mathrm{dl}}}$ & $\begin{array}{l}\mathbf{R}_{\mathrm{s}} \\
(\mathrm{W})(\end{array}$ & $\left(\begin{array}{c}\mathbf{R}_{\mathrm{c}} \\
\left(\mathrm{W} \cdot \mathrm{cm}^{2}\right)\end{array}\right.$ & $\begin{array}{c}C P E_{c} \\
\left(S \cdot s^{n} \cdot \mathrm{cm}^{-2}\right) \\
(n)\end{array}$ & $\begin{array}{c}R_{\mathrm{t}} \\
\left(W \cdot \mathrm{cm}^{2}\right)\end{array}$ & $\begin{array}{c}\mathrm{CPE}_{\mathrm{dl}} \\
\left(\mathrm{S} \cdot \mathrm{s}^{\mathrm{n}} \cdot \mathrm{cm}^{-2}\right) \\
\text { (n) }\end{array}$ & $\operatorname{chi}^{2}$ \\
\hline \multirow{2}{*}{ a) } & 1250 & - & - & $9,8 \times 10^{3} 4,0 \times 10^{-6}$ & 239 & - & - & $1, \times 10^{4}$ & $\begin{array}{c}1,7 \times 10^{-5} \\
(n=0,7)\end{array}$ & $4,1 \times 10^{-3}$ \\
\hline & 11263 & - & - & $8,0 \times 10^{3} 6,7 \times 10^{-6}$ & 415 & - & - & $8,6 \times 10^{3}$ & $\begin{array}{l}1,5 \times 10^{-5} \\
(n=0,7)\end{array}$ & $8,0 \times 10^{-4}$ \\
\hline \multirow{2}{*}{ b) } & 1147 & $2,0 \times 10^{3}$ & $5,4 \times 10^{-7}$ & $4,5 \times 10^{5} 2,1 \times 10^{-6}$ & 110 & $1,3 \times 10^{3}$ & $\begin{array}{c}1,1 \times 10^{-5} \\
(n=0,7)\end{array}$ & $1,7 \times 10^{6}$ & $\begin{array}{c}8,9 \times 10^{-6} \\
(n=0,9)\end{array}$ & $1,8 \times 10^{-4}$ \\
\hline & 11 & - & - & $2,8 \times 10^{4} 1.1 \times 10^{-5}$ & 58 & - & - & $3,2 \times 10^{4}$ & $\begin{array}{c}2,1 \times 10^{-5} \\
(n=0,8)\end{array}$ & $7,4 \times 10^{-4}$ \\
\hline
\end{tabular}

Los resultados obtenidos fueron muy diferentes cuando la aleación AZ31 se sometía a un proceso de conversión química en una solución de ácido fluorhídrico. Los ensayos con la aleación AZ31 modificada superficialmente en medio de cultivo celular, tanto en ausencia como en presencia de células Saos-2 y MC3T3-E1, mostraron la ausencia de burbujas de hidrógeno y precipitados en los bordes y superficie del material durante todo el tiempo de ensayo. Estos datos se correlacionan con los mapas de potencial (Fig. 3) en donde se observa que la capa de fluoruro de magnesio que cubre la superficie del material disminuye notablemente la reactividad de la aleación frente a la corrosión. Estos datos también coinciden con los resultados de EIS (Fig. 4 b)), en los que la presencia de la capa de fluoruro de magnesio aumenta la resistencia a la corrosión de este material. No obstante, y a modo de ejemplo, en la figura 6 b) se muestra cómo la pérdida del recubrimiento se inicia en los bordes y aristas vivas del material en forma de corrosión filiforme, aunque se pudo observar que en las zonas donde el recubrimiento estaba intacto existía siempre crecimiento celular. La figura 7 a) muestra la presencia de células Saos-2 sobre la superficie metálica de la aleación AZ31 con recubrimiento de fluoruro de magnesio y la adhesión de estas células a la superficie del material, como queda reflejado por la presencia en éstas de filopodios, que aparecen a modo de prolongaciones ó extensiones de las células. La observación a mayor aumento del material permite visualizar una capa continua de células en monocapa de revestimiento sobre la superficie del propio metal (Fig. 7 b)). Resultados equivalentes a éstos se obtuvieron cuando los materiales recubiertos con fluoruro de magnesio fueron ensayados con la línea no tumoral de ratón MC3T3-E1. Así, la figura 7 c) muestra de forma evidente, mediante tinción con el reactivo Hoechst que tiñe el ADN celular, la existencia de células osteoblásticas tanto en el pocillo de cultivo como sobre la superficie del material. Todos estos resultados indican que la aleación AZ31 con recubrimiento de fluoruro de magnesio tiene una buena biocompatibilidad con las líneas osteoblásticas ensayadas, de tal forma que la presencia de la capa protectora de fluoruro de magnesio sobre la aleación hace que el aumento de la resistencia a la corrosión en el medio celular sea suficiente para permitir el crecimiento celular.

\subsection{Ensayos de biocompatibilidad in vivo}

Los ensayos in vivo de la aleación AZ31 en estado de recepción y recubierta con fluoruro de magnesio se llevaron a cabo en ratas Wistar. La figura 8 muestra 

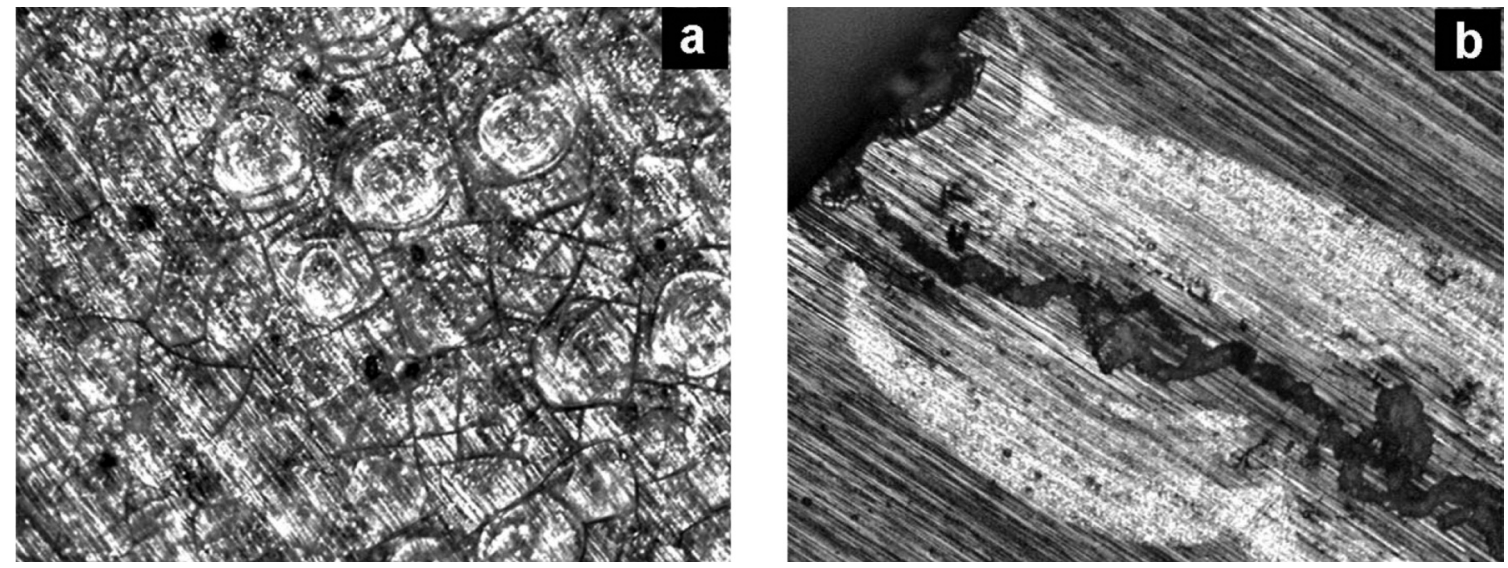

Figura 6. Morfología del ataque por corrosión de la aleación de magnesio AZ31 en cultivo con células osteoblásticas Saos-2: a) Corrosión por picadura en el material en estado de recepción y b) Corrosión filiforme en el material con recubrimiento de fluoruro de magnesio.

Figure 6. Corrosion morphology of AZ31 magnesium alloy in culture with the osteoblastic cell line Saos-2: a) Pitting corrosion of as-received material and b) Filiform corrosion of magnesium fluoride-coated material.
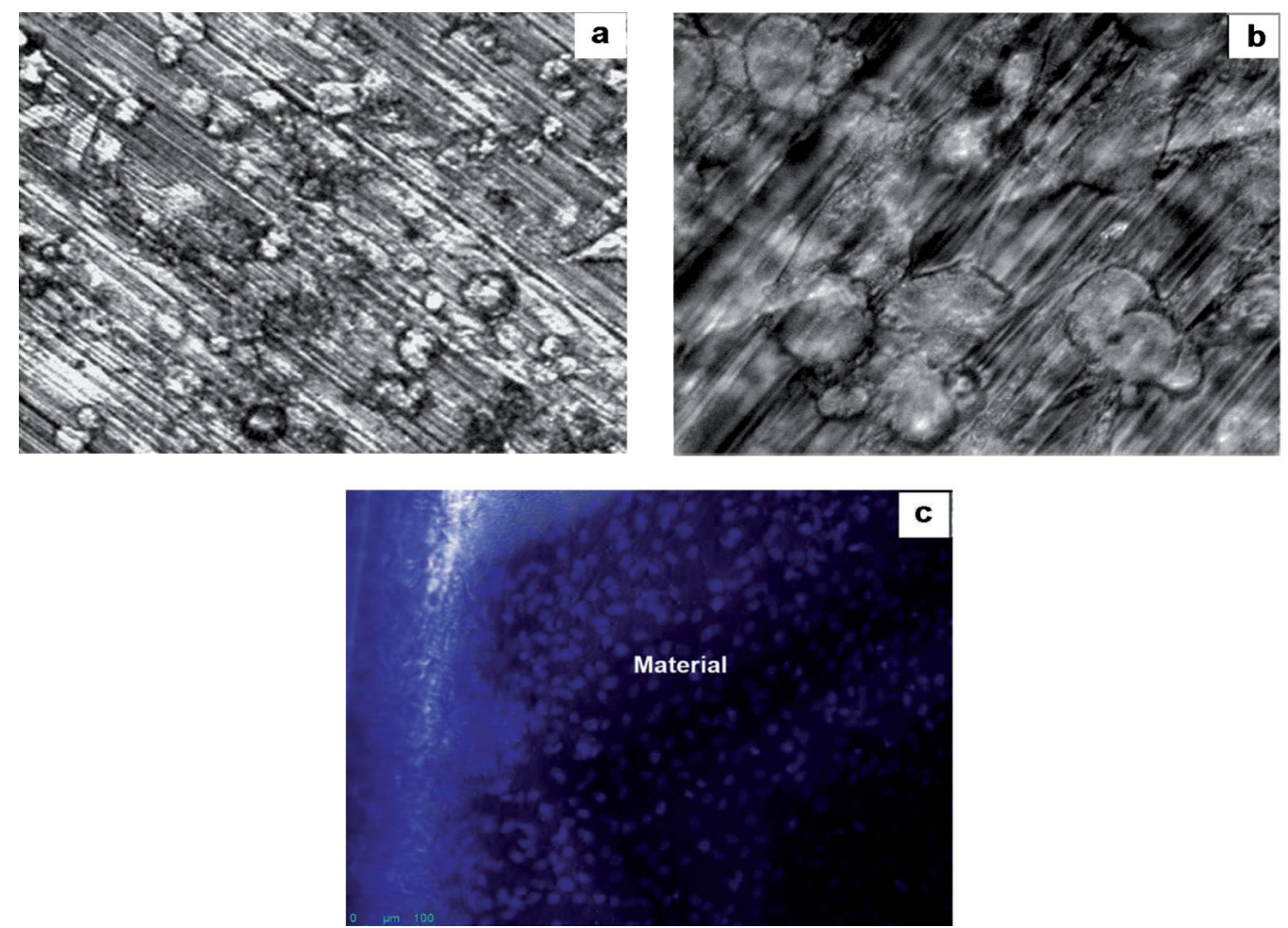

Figura 7. Biocompatibilidad in vitro de la aleación de magnesio AZ31 con recubrimiento de fluoruro de magnesio: a) Células Saos-2 sobre la superficie del material tras 11 días de cultivo, b) Capa continua de células a modo de epitelio sobre la superficie (detalle de la imagen anterior, 500× y c) Células MC3T3-E1 crecidas durante 7 días sobre el material (tinción con Hoechst 33258).

Figure 7. In vitro biocompatibility of the AZ31 magnesium alloy coated with magnesium fluoride: a) Saos-2 cells grown on the surface for 11 days, b). Continuous cell layer of Saos-2 forming an epithelium on the material surface (magnification of the former image, 500x) and c) MC3T3-E1 cells grown for 7 days on the material (Hoechst 33258 staining). 

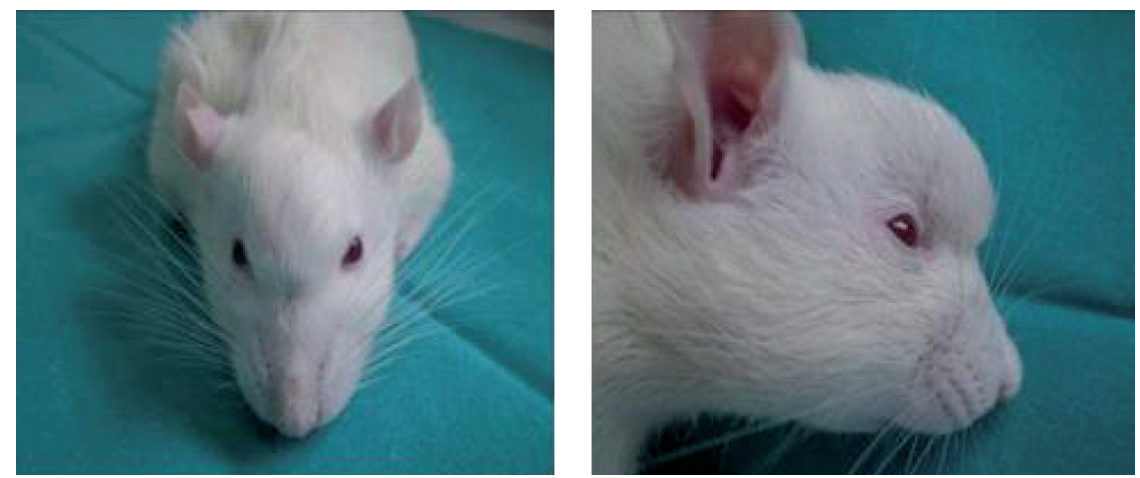

Figura 8. Abultamiento debido a la producción de hidrógeno gas como consecuencia de la reacción catódica de corrosión de la aleación de magnesio AZ31 en estado de recepción tras 15 días de implantación en rata Wistar.

Figure 8. Enlargement due to hydrogen gas formation from the cathodic reaction of the corrosion process of the as-received AZ31 magnesium alloy after 15 days of implantation in Wistar rat.

imágenes de la cabeza de los animales con signos evidentes del proceso de corrosión de la aleación en estado de recepción en contacto con los fluidos fisiológicos, como son los abultamientos debidos a la producción de hidrógeno gas (reacción catódica de corrosión). La formación de estas bolsas de gas aparece aproximadamente a los 15 días en las ratas en las que se había implantado aleación en estado de recepción y a los 30 días en aquellas con implantes del material recubierto.

La figura 9 muestra la degradación de la aleación AZ31 con recubrimiento de fluoruro de magnesio en función del tiempo de implantación en el animal de experimentación. Según se ha observado, el material implantado (Fig. 9 a)) sufre durante la primera semana una reacción de encapsulamiento mediante la formación de tejido fibroso (Fig. 9 b)). Como se muestra en la figura 9 c), el proceso de degradación del material se inicia en sus bordes y aristas (zonas activas de corrosión) y evoluciona dando lugar a la formación de productos blanquecinos (óxidos e hidróxidos de magnesio) sobre todo el implante, el cual llega prácticamente a desaparecer a los 48 días (Fig. 9 d)). Como dato gravimétrico, los porcentajes de pérdida de masa producidos a los 24 días de implantación respecto a la masa inicial del material se encontraron en el orden del $13 \%$ para la aleación en estado de recepción y del $8 \%$ para la modificada superficialmente, confirmando así el efecto protector del recubrimiento. Los resultados obtenidos respecto a la pérdida de masa de los implantes son consecuencia de la reacción anódica de disolución y se correlacionan con

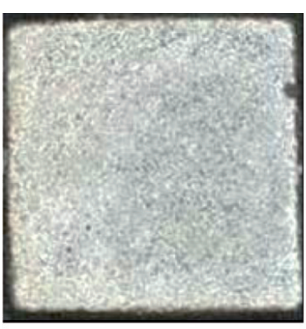

a)

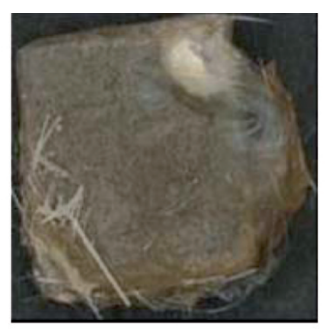

b)

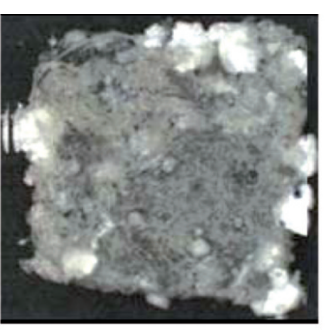

c)

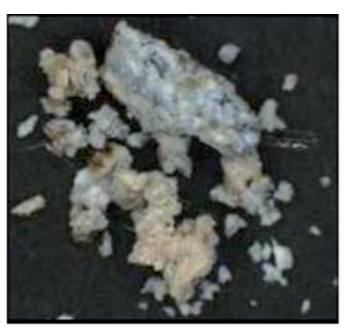

d)

Figura 9. Secuencia de degradación de la aleación AZ31 con recubrimiento de fluoruro de magnesio para diferentes tiempos de permanencia en rata Wistar: a) tiempo cero, b) 7 días, c) 24 días y d) 48 días.

Figure 9. Degradation sequence of AZ31 alloy coated with magnesium fluoride for different permanence times in Wistar rat: a) initial state, b) 7 days, c) 24 days and d) 48 days. 
los datos anteriormente mencionados referentes a la reacción catódica de formación de hidrógeno, de evolución más lenta en el material con recubrimiento. En este caso, el estudio histológico del tejido en la zona del implante muestra bajo la dermis una capa de tejido neoformado muy compacta, con un espesor medio de $0,27 \mathrm{~mm}$ y con pocos fibroblastos, como se puede observar en la figura 10 .

En definitiva, los resultados obtenidos de los ensayos in vivo muestran una buena correlación con los obtenidos en la experimentación in vitro, tanto desde el punto de vista de corrosión como de viabilidad celular, mostrando que la aleación AZ31 recubierta con fluoruro de magnesio es un material biodegradable y reabsorbible que puede ser adecuado para su uso como implante temporal.

\section{CONCLUSIONES}

- Los resultados obtenidos en este trabajo muestran que las propiedades mecánicas de la aleación AZ31 son superiores a los requisitos mecánicos del hueso.

- El tratamiento de conversión química de la aleación AZ31 en ácido fluorhídrico mejora su comportamiento frente a la corrosión debido al recubrimiento de fluoruro de magnesio generado.

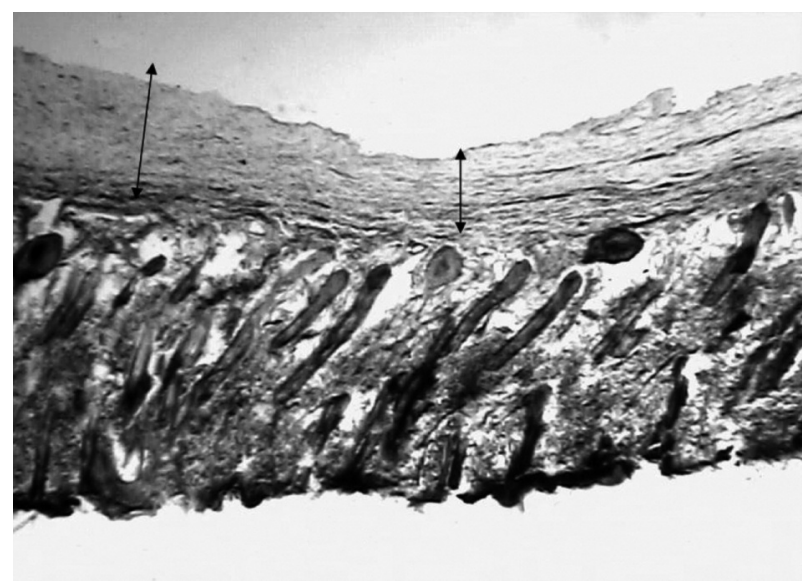

Figura 10. Corte histológico en la zona del implante de AZ31 con recubrimiento de fluoruro de magnesio tras 48 días de implantación en rata Wistar (espesor medio de la capa de tejido óseo neoformado ( $\uparrow)$ : 0,27 mm).

Figure 10. Histological tissue around the implant of AZ31 alloy coated with magnesium fluoride after 48 days of implantation in Wistar rat (mean thickness of the new bone tissue layer $(\uparrow)$ : $0.27 \mathrm{~mm}$ ).
Dicho tratamiento produce cambios en las propiedades electroquímicas de la superficie del material que aumentan su resistencia frente a la corrosión y le hacen compatible con el crecimiento in vitro de células osteoblásticas y con la formación in vivo de nuevo tejido óseo. Con estos resultados puede proponerse la aleación AZ31 con recubrimiento de fluoruro de magnesio para su potencial aplicación como implante biodegradable y reabsorbible para reparaciones óseas.

\section{Agradecimientos}

Los autores agradecen al MICINN la financiación de esta investigación a través del proyecto MAT 2008-06719-C-01-02-03. JAdV agradece a la CYCIT por el proyecto MAT 2006-02672 y al CSIC por el proyecto Intramural 200860I124. MC agradece al CSIC la concesión de un contrato JAE-Doc.

\section{REFERENCIAS}

[1] T. Hanawa, Mater. Sci. Eng. C. 24 (2004) 745-752.

[2] M.P. Staiger, A.M. Pietak, J. Huadmai y G. Dias, Biomaterials 27 (9) (2006) 1.728-1.734.

[3] S.F. Yang, K.F. Leong, Z.H. Du y C.K. Chua, Tissue Eng. 7(6) (2001) 679-89.

[4] Y. Al-Abdullat, S. Tsutsumi, N. Nakajima, M. Ohta, H. Kuwahara y K. Ikeuchi, Mater. Trans. 42 (2001) 1.777-1.780.

[5] R. Zeng, W. Dietzel, F. Witte, N. Hort y C. Blawert, Adv. Eng. Mater. 10 (2008) B03-B14.

[6] G.L. Song, Corros. Sci. 49 (2007) 1.696-1.701.

[7] F. Witte, N. Hort, C. Vogt, S. Cohen, K.U. Kainer, R. Willumeit y F. Feyerabend, Curr. Opin. Solid State Mater. Sci. 12(5-6) (2008) 63-72.

[8] M. Álvarez-López, M.D. Pereda, J.A. del Valle, M. Fernández-Lorenzo, M.C. García-Alonso, O.A. Ruano y ML Escudero, Acta Biomater. 6 (2010) 1.763-1.771.

[9] X. Gu, Y. Zheng, Y. Cheng, S. Zhong y T. Xi, Biomaterials 30 (2009) 484-498.

[10] F. Witte, V. Kaese, H. Haferkamp, E. Switzer, A. Meyer-Lindenberg y C.J. Wirth, Biomaterials 26 (2005) 3.557-3.563.

[11] K. Chiu, M. Wong, F. Cheng y H. Man, Surf. Coat. Technol. 202 (2007) 590-598.

[12] M. Carboneras, L.S. Hernández, J.A. del Valle, M.C. García-Alonso y M.L. Escudero, J. Alloys Comp. 496(1-2) (2010) 442-448.

[13] J. Gray y B. Luan, J. Alloys Comp. 336 (2002) 88-113. 
[14] A. Doyle, J.B. Griffiths y D.G. Newell, Testing for Microbial contamination, in: A. Doyle, J.B. Griffiths, D.G. Newell, (Eds.), Cell \& Tissue Culture: Laboratory Procedures, John Wiley \& Sons Ltd, Vol I, West Sussex, England, 1995, pp. 7A:1.2.

[15] J.A. del Valle, F. Carreño y O.A. Ruano, Acta Mater. 54 (2006) 4.247-4.259.

[16] V. Caesel, P.-T. Tai, Fr.-W. Bach, H. Haferkamp, F. Witte y H. Windhagen, Proceedings of the Sixth
International Conference on Magnesium Alloys and Their Applications, K.U. Kainer (Ed.), 2003, pp. 534-539.

[17] M. Carboneras, L.A. Hernández-Alvarado, Y.E. Mireles, L.S. Hernández, M.C. GarcíaAlonso y M.L. Escudero, Rev. Metal. Madrid 46 (2010) 86-92.

[18] Z. Li, X. Gu, S. Lou e Y. Zheng, Biomaterials 29 (2008) 1.329-1.344. 